\title{
Health and Community-Based Services for Individuals with Neurological Conditions
}

\author{
Sarah E.P. Munce, Kristen B. Pitzul, Sara J.T. Guilcher, Tarik Bereket, Mae Kwan, \\ James Conklin, Joan Versnel, Tanya Packer, Molly Verrier, Connie Marras, \\ Richard Riopelle, Susan B. Jaglal
}

\begin{abstract}
Background: The current study involves a national survey of healthcare providers who offer services for individuals with a variety of neurological conditions. It aims to describe the provision of health and community-based services as well as the admission criteria, waitlist practices, and referral sources of these services. Methods: An online survey was directed at administrators/managers from publicly funded hospital programs, long-term care homes, and community-based healthcare provider agencies that were believed to be providing information and/or services to patients with a variety of neurological conditions. Results: Approximately $60 \%(n=254)$ of respondents reported providing services in either urban/suburban areas or rural/remote areas only, whereas the remaining $40 \%(n=172)$ provided services regardless of patient location. A small proportion of respondents reported providing services for individuals with dystonia (28\%), Tourette syndrome $(17 \%)$, and Rett syndrome (13\%). There was also a paucity of diverse healthcare professionals across all institutions, but particularly mental healthcare professionals in hospitals. Lastly, the majority of respondents reported numerous exclusion criteria with regard to service provision, including prevalent comorbid conditions. Conclusions: If the few services provided for these neurological patient populations exclude common comorbidities, it is likely that there will be no other place for these individuals to seek care.
\end{abstract}

RÉSUMÉ: Services de santé et services communautaires destinés aux personnes souffrant de troubles neurologiques. Contexte: La présente étude repose sur une enquête nationale menée auprès de fournisseurs qui offrent des services de santé à des personnes atteintes de divers troubles neurologiques. Elle vise à décrire la prestation de services dans des hôpitaux et des organismes communautaires mais aussi à déterminer leurs critères d'admissibilité, leurs pratiques de gestion des listes d'attente et le type de professionnels qui ont procédé à l'aiguillage en amont. Méthodes: Un sondage en ligne a été envoyé à des gestionnaires de services hospitaliers bénéficiant de financement public, d'établissements de soins de longue durée et d'organismes communautaires ayant fourni, estimait-on, des renseignements ou des services à des patients atteints d'une variété de troubles neurologiques. Résultats: Environ 60 \% $(n=254)$ des répondants ont admis n'offrir des services que dans des régions urbaines/périurbaines ou dans des régions rurales/éloignées tandis que $40 \%$ d'entre eux $(n=172)$ ont affirmé offrir ces services peu importe le lieu d'origine des patients. Une faible proportion de répondants a affirmé offrir des services à des personnes atteintes de dystonie $(28 \%)$, du syndrome de Gilles de La Tourette (17\%) et du syndrome de Rett (13\%). On a aussi noté une pénurie de professionnels de la santé dans l'ensemble des établissements, en particulier des professionnels de la santé mentale au sein des hôpitaux. Finalement, la majorité des répondants a fait état de nombreux critères d'exclusion quant à la prestation de services, ce qui inclut des comorbidités antérieures. Conclusions: Considérant que les quelques établissements qui offrent des services à ce groupe de patients excluent d'emblée des comorbidités courantes, il est à parier que ces mêmes patients ne pourront être soignés ailleurs.

Keywords: neurological, health services, community, national, survey

doi:10.1017/cjn.2017.207

Can J Neurol Sci. 2017; 44: 670-675

\section{BACKGROUND}

It is expected that neurological diseases, disorders, and injuries will become the leading cause of morbidity and mortality in
Canada over the next 20 years. ${ }^{1}$ In 2008 , stakeholders representing patients with 11 neurological conditions (Alzheimer's disease, amyotrophic lateral sclerosis [ALS], brain tumors, cerebral palsy,

From the Brain and Spinal Cord Rehabilitation Program, Toronto Rehabilitation Institute, Toronto, Ontario, Canada (SM, MV, CM); the Institute of Health Policy Management and

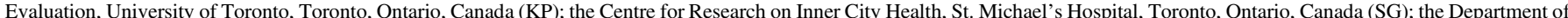

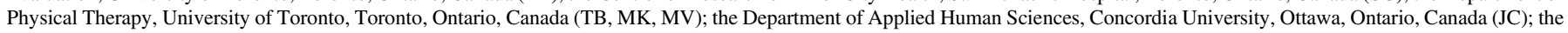

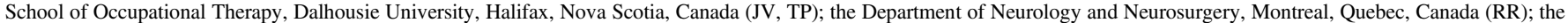
Department of Physical Therapy, Toronto Rehabilitation Institute, University of Toronto, Toronto, Ontario Canada (SJ). Received May 19, 2016. Final Revisions Submitted April 13, 2017. Date of Acceptance April 18, 2017.

Correspondence to: Sarah Munce, Toronto Rehabilitation Institute, Brain and Spinal Cord Rehabilitation Program, 550 University Avenue, Toronto, Ontario, M5G 2A2, Canada.

E-mail: sarah.munce@uhn.ca 
epilepsy, head injury, headaches, multiple sclerosis, Parkinson's disease, spinal injuries, and stroke) joined forces to establish the Neurological Health Charities of Canada (NHCC). The NHCC aims to advocate for patients with these conditions across the lifespan and continuum of care. ${ }^{1}$ These conditions have a significant impact on the individual, family members, and caregivers, as well as on the healthcare system.

More than $9 \%$ of acute-care hospitalizations and $19 \%$ of patient days in acute-care hospitals in Canada in 2004-2005 were for patients with one of the above priority neurological conditions as a primary or secondary diagnosis. ${ }^{2}$ Furthermore, the total cost of these 11 priority neurological conditions was estimated to be $\$ 8.8$ billion in $2000-2001$, representing $6.7 \%$ of the total attributable cost of illness in Canada. ${ }^{2}$

While this high healthcare utilization has been documented for specific neurological conditions, ${ }^{3,4}$ there is an overall lack of information on health service needs and gaps. Without comprehensive information, it is difficult for federal, provincial, or municipal policy makers, as well as for other relevant stakeholders, to plan and implement appropriate programs and services.

Given this lack of information, the current study involves a national survey of healthcare providers who offer services for individuals with a variety of neurological conditions. This study aims to describe the provision of health and community-based services, as well as the admission criteria, waitlist practices, and referral sources of these services. The study was one of a number of studies that comprised a large Canadian study, the National Population Health Study of Neurological Conditions (NPHSNC), which examined all aspects of the burden of disease associated with neurological conditions. ${ }^{5}$

\section{METHODS}

\section{Overall Approach}

A knowledge-to-action framework was employed to guide the study design. ${ }^{6}$ This means that stakeholders were consulted and involved throughout study development, implementation, and dissemination, to help ensure that the study findings would be relevant and actionable. ${ }^{7}$ A stakeholder advisory group (SAG) representing all of the NHCC member organizations (which had grown from the initial 11 to 18 members by the time of the study's inception) provided the stakeholder perspective to the project team. Approval from the research ethics board at the University of Toronto was obtained.

\section{Participant Recruitment}

An online survey was directed at administrators/managers from publicly funded hospital programs (both inpatient and outpatient clinics), long-term care (LTC) homes, and communitybased healthcare provider agencies that were believed to be providing information and/or services to patients with any neurological condition. The Online Guide to Canadian Healthcare Facilities was used to identify potential facilities for participation. ${ }^{8}$ The guide contained mailing addresses for almost 7,000 facilities across Canada. ${ }^{8}$ These facilities were grouped into the following categories: hospitals, including acute-care, trauma, rehabilitation and children's treatment centers/hospitals; community-based organizations (CBOs), including home-care and community health centers; and LTC facilities.

It was determined a priori that there were 837 hospitals, 1,550 nursing homes and LTC facilities, 568 home-care organizations, and 1670 community-based healthcare provider facilities that could be included for our sampling frame $(n=4,625)$. Additional facilities were restricted from our potential sample based on the following criteria: (1) facilities with duplicate contacts $(n=50)$; (2) facilities that did not have full contact information for at least one individual $(n=1513)$; and (3) all privately funded LTC facilities $(n=730)$. These exclusion criteria resulted in 2,332 potential survey participants $(n=4,625-2,293=2,332)$. In addition, 451 individuals who were in the sampling frame for an earlier phase of the study (key informant phase) ${ }^{9}$ but were not contacted for an interview and who were not policy makers were included in the sample for the survey. As a result, our final survey sample was $2,783(N=2,332+451=2,783)$.

\section{Items for Survey Instrument}

Preliminary results from a scoping review and key informant interviews (two phases informing the national NPHSNC study) helped to develop and refine the relevant content areas for the online survey. In addition, a survey on community and health services for acquired brain injury that our research team had previously developed and implemented was used to inform the content area of the present survey. ${ }^{10}$ After developing a draft of the survey, it was pilot-tested with members of the SAG to receive feedback about its clarity, relevance, and wording. The survey was updated based on feedback from the pilot testing. To address the current study objectives and in keeping with identified areas from the scoping review and key informant interviews, the final survey included the following content areas: population(s) served (eligibility/admission criteria); geographical coordinates of the services (postal code); type of services provided (e.g., rehabilitation, education, counseling, medical, caregiver support); utilization of services; waitlists; and time to access services. While the survey focused on the 11 priority neurological conditions of the NHCC, survey respondents could indicate if their organization provided services for other neurological conditions.

\section{Survey Distribution}

A modified Dillman approach was employed for survey distribution. ${ }^{11}$ Invitation letters were sent via surface mail with a website address (www.NeuroSurvey.utoronto.ca) asking recipients to complete the survey online. English-language invitation letters were distributed in all provinces and territories except Quebec and New Brunswick, which received bilingual (French and English) letters. Each survey invitation had a unique study ID so that reminder notices could be sent to nonrespondents. Participants had approximately four weeks to complete the survey, with a postcard reminder sent at two weeks that contained the web survey link. ${ }^{11}$ Surveys were available in both English and French. The original survey was written in English and then translated into French (and back-translated into English to ensure accuracy) by a translator who had previous experience with translating documents for studies on neurological research. 


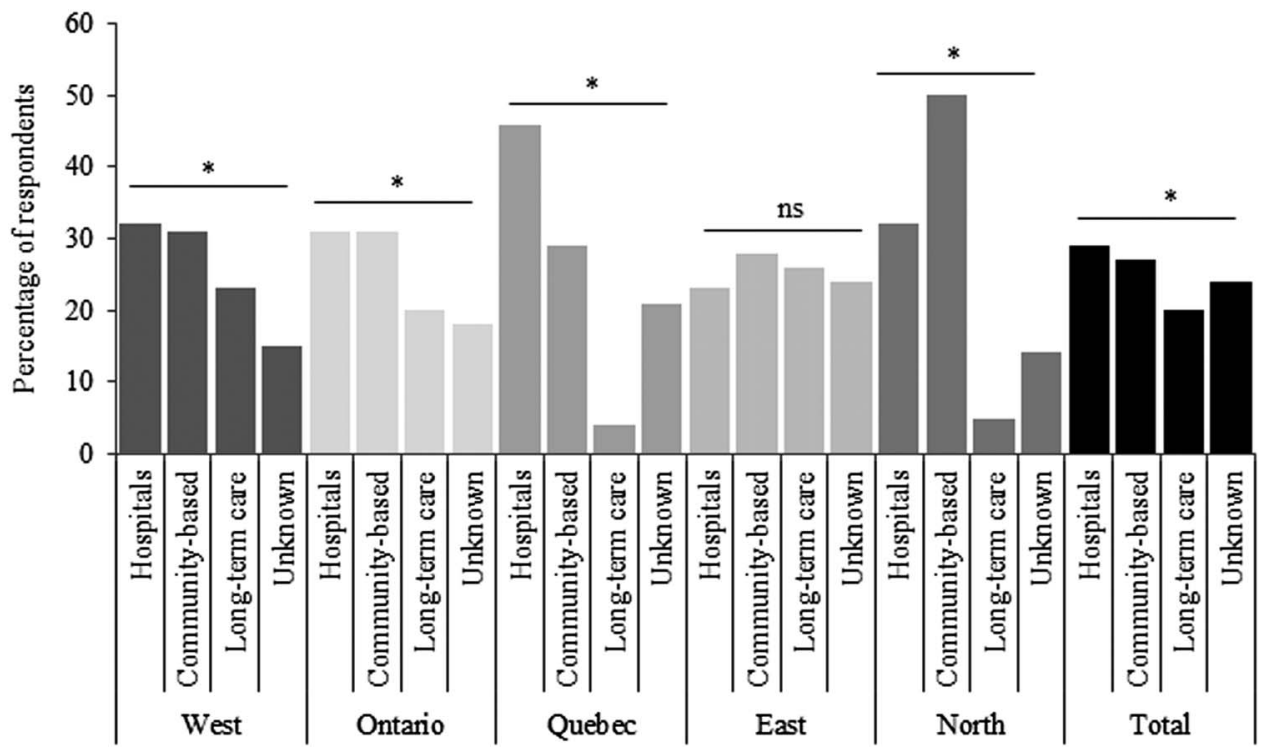

Figure 1: Facility types for each region (West, Ontario, Quebec, East, and North) for all survey respondents. There was a total of 469 respondents. The values of $p$ for each region were as follows: $p_{\text {West }}=0.023 ; p_{\text {Ontario }}=0.036 ; p_{\text {Quebec }}=0.001 ; p_{\text {East }}=0.367 ; p_{\text {North }}=0.033 ; p_{\text {total }}=0.001$.

\section{Data Analysis}

Descriptive analyses were performed for continuous data, and the appropriate measures of central tendency and variance were calculated. All analyses were completed using IBM SPSS Statistical Software (v. 23; IBM, Armonk, New York). ${ }^{12}$

\section{RESULTS}

\section{Response Rate and Representation}

A total of 2,783 invitations were sent, and there were 469 respondents $(17 \%)$ representing hospitals $(29 \%, n=134)$, CBOs (27\%, $n=125)$, and LTC facilities (20\%, $n=96)$ (Figure 1). The remaining $24 \%(n=114)$ of respondents did not identify their facility type. The geographic variation among responders was consistent with the distribution of the Canadian population across provinces, with $40 \%(n=187)$ of respondents from Ontario; $28 \%$ $(n=131)$ from Manitoba, Saskatchewan, Alberta, and British Columbia; $10 \%$ from Quebec $(n=56) ; 19 \%$ from the Atlantic Provinces $(n=93)$; and $1 \%$ from the North $(n=22)$ (Figure 1). The majority of respondents participated in the English-language survey $(94 \%)$.

Table 1: Facility type by rurality for all survey respondents who identified facility type $(N=426)$

\begin{tabular}{l|c|c|c|c}
\hline & \multicolumn{3}{|c|}{ Rurality } & \\
\hline $\begin{array}{l}\text { Facility type, } \\
\boldsymbol{n}(\%)\end{array}$ & Both & $\begin{array}{c}\text { Urban/ } \\
\text { suburban }\end{array}$ & $\begin{array}{c}\text { Rural/ } \\
\text { remote }\end{array}$ & Total \\
\hline Hospitals & $47(35.1 \%)$ & $38(28.4 \%)$ & $47(35.1 \%)$ & $134(100 \%)$ \\
\hline $\begin{array}{l}\text { Community- } \\
\text { based }\end{array}$ & $72(57.6 \%)$ & $32(25.6 \%)$ & $16(12.8 \%)$ & $120(100 \%)$ \\
\hline Long-term care & $19(19.8 \%)$ & $37(38.5 \%)$ & $36(37.5 \%)$ & $92(100 \%)$ \\
\hline Total & $172(36.7 \%)$ & $127(27.1 \%)$ & $127(27.1 \%)$ & $426(100 \%)$ \\
\hline
\end{tabular}

A total of $30 \%(n=127)$ of respondents reported providing services only in urban/suburban areas, 30\% $(n=127)$ provided services only in rural/remote areas, and $40 \%(n=172)$ reported providing services in both urban/suburban and rural/remote areas (Table 1). The distribution of service providers in urban/suburban compared to rural/remote areas differed within each facility type (Table 1).

\section{Use and Availability of Services}

The majority of respondents indicated providing services for individuals with stroke $(71 \%, n=335)$, Parkinson's disease (65\%, $n=303)$, Alzheimer's disease $(65 \%, n=307)$, acquired/ traumatic brain injury $(59 \%, n=277)$, and multiple sclerosis $(57 \%, n=268)$. Only a small proportion of respondents reported providing services for individuals with dystonia $(28 \%, n=133)$, Tourette syndrome $(18 \%, n=82)$, and Rett syndrome $(13 \%$, $n=63$ ) (Figure 2). Overall, a lower proportion of service providers reported providing services for children (i.e., 0-17 years) versus services for adults (Figure 2). This difference in proportions was particularly notable for spinal cord injury (15.4 vs. $33.3 \%$ ) and acquired/traumatic brain injury (16.8 vs. $46.1 \%$ ).

Other healthcare professionals, including physiotherapists and nurses, delivered most of the care across all three facility types. Overall, a low proportion of mental healthcare professionals was noted (e.g., $40 \%[n=54]$ and $29 \%[n=39]$ reported having general psychology/psychiatry and neurospecific psychology/psychiatry, respectively, in hospitals, while only $9 \%[n=9]$ and $2 \%$ $[n=2]$ reported having general psychology/psychiatry and neurospecific psychology/psychiatry at LTC facilities). As observed in general psychology/psychiatry and neurospecific psychology/psychiatry, the number and type of staff employed and in-house services provided varied by facility type. For example, only $28 \%(n=37)$ of respondents from hospitals reported having a neurologist, and there were very few respondents from CBOs $(3 \%, n=4)$ or LTC facilities $(0 \%, n=0)$ 


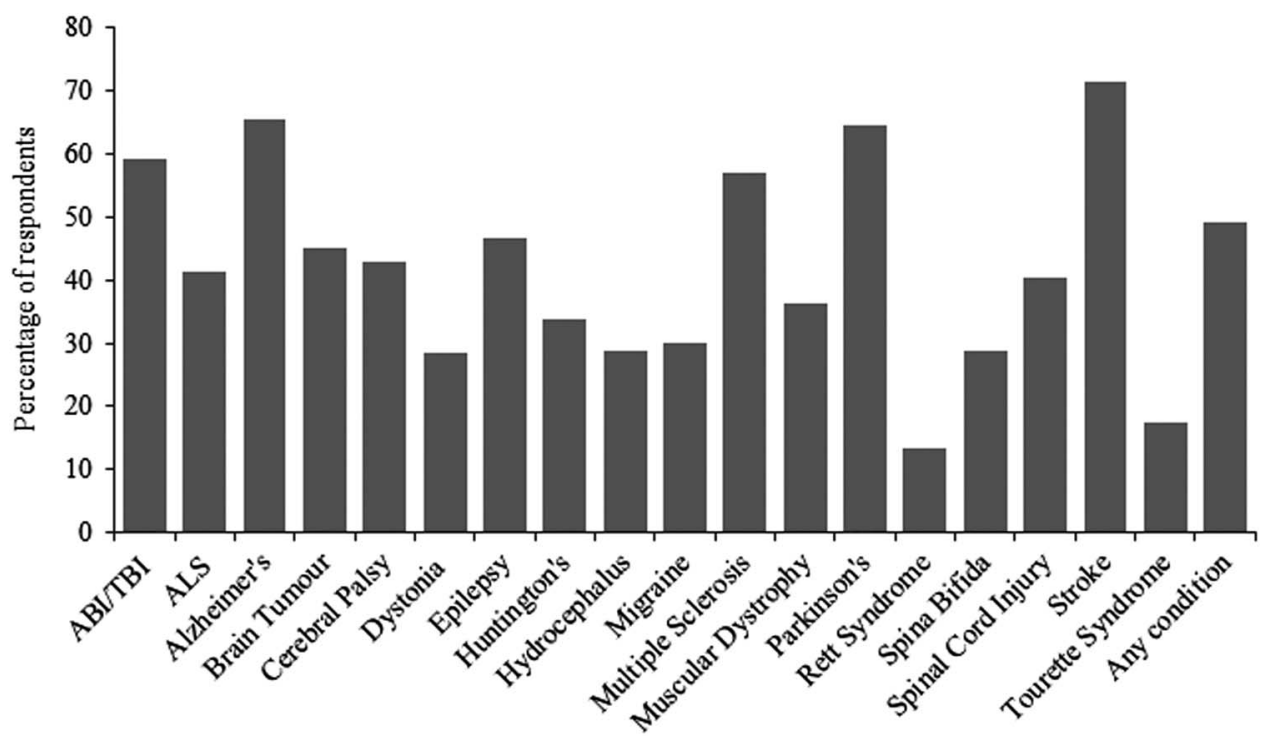

Figure 2: Percentage of respondents (total $N=469$ ) who currently offer services for individuals diagnosed with at least one of the included neurological conditions. ABI/TBI=acquired brain injury/ traumatic brain injury; $A L S=$ amyotrophic lateral sclerosis; Alzheimer's =Alzheimer's disease; Huntington's = Huntington's Disease; Parkinson's = Parkinson's disease.

who had a neurologist. As expected, LTC facilities had a higher proportion of personal support workers $(73 \%, n=70)$ providing services compared to hospitals $(39 \%, n=52)$ or CBOs $(37 \%, n=46)$ (Table 2).

\section{Exclusion Criteria and Waitlist Practices and Referral Sources}

About a third $(n=153)$ of respondents cited psychiatric diagnosis/severe behavioral disorders and substance abuse as exclusion criteria for their organizations. Similarly, $31 \%(n=147)$ of respondents cited medical instability, degenerative medical conditions, and/or presence of comorbidities as exclusion criteria for services. Age was reported as an exclusion criterion among $21 \%$ $(n=97)$ of respondents. Finally, 28\% $(n=130)$ of respondents reported no exclusion criteria for the services at their organization.

Some $72 \%(n=248)$ of respondents reported that their organization maintained a waitlist. Where a waitlist was employed, $41 \%$ $(n=190)$ of service providers reported that the number of spaces available was an important factor influencing the length of time on the waitlist. A total of $60 \%(n=280)$ of respondents reported that referrals to their organization came from acute-care hospitals. Similarly, 58\% $(n=274)$ reported that referrals came from general practitioners/family physicians, while $45 \%(n=210)$ reported that referrals came from specialists. Most referrals to community-based providers were from family or friends $(76.8 \%, n=96)$.

\section{DISCUSSION}

The current study aimed to describe the provision of health and community-based services, as well as the admission criteria, waitlist practices, and referral sources of these services from the perspective of administrators/managers across Canada. Our results revealed that there are few services for individuals with neurological conditions that have low prevalence and incidence, including dystonia, Tourette syndrome, and Rett syndrome.
Furthermore, there are few healthcare professionals (e.g., physicians, psychologists) practicing at any of the three facility types, but particularly at CBOs. Specifically, there was an overall lack of psychological/psychiatric services. While this finding may not be particularly surprising in CBOs, which can represent a diverse range of health services and programs (e.g., case management, supportive housing), ${ }^{13}$ the lack of healthcare professionals and particularly mental healthcare professionals in hospitals represents a gap in care. Service providers reported extensive use of exclusion criteria, including challenging behaviors and prevalent comorbid conditions, both of which are often associated with neurological conditions. These exclusions are likely to restrict access to those with the greatest need. These exclusion criteria may be the result of the reported lack of trained healthcare professionals (i.e., psychiatrists, psychologists) to manage/treat these subpopulations at each of the different facilities. The study findings may also suggest that service delivery is uncoordinated, with $30 \%$ of organizations not even maintaining a waitlist. However, it is acknowledged that a waiting list might not be maintained because individuals are already being served. At the same time, the fact that the majority of institutions have waiting lists for services may indicate that existing services are not responding to the need for services.

While it is recognized that, among the more rare neurological conditions (i.e., Tourette syndrome, Rett syndrome, and dystonia), low provision of services may be in response to their relatively low prevalence and their lack of inpatient requirements (most persons would not necessarily require an acute-care or longterm care admission), the results of our study suggest a low provision of services across the lifespan for persons living with these conditions in Canada. This is consistent with an overall lack of research on guiding frameworks and models of service provision for individuals with these conditions. ${ }^{14,15}$ Future research should focus on why such a gap exists in the provision of services for these individuals. At the same time, it should be acknowledged 
Table 2: Type of service providers available at respondents institutions, by institution-type $(N=469)$

\begin{tabular}{|c|c|c|}
\hline Facility type & Service providers & $n(\%)$ \\
\hline \multirow[t]{8}{*}{ Hospital } & $\begin{array}{l}\text { Other healthcare professionals } \\
\text { (e.g., physiotherapists) }\end{array}$ & $124(92.5 \%)$ \\
\hline & General practitioners & $83(61.9 \%)$ \\
\hline & General psychology/psychiatry & $54(40.3 \%)$ \\
\hline & Neurologists & $37(27.6 \%)$ \\
\hline & Neurospecific psychology/psychiatry & $39(29.1 \%)$ \\
\hline & Nonpsychiatric specialists & $76(56.7 \%)$ \\
\hline & Nurses & $115(85.8 \%)$ \\
\hline & Personal support workers & $52(38.8 \%)$ \\
\hline \multirow[t]{8}{*}{ Community-based } & $\begin{array}{l}\text { Other healthcare professionals } \\
\text { (e.g., physiotherapists) }\end{array}$ & $81(64.8 \%)$ \\
\hline & General practitioners & $25(20.0 \%)$ \\
\hline & General psychology/psychiatry & $17(13.6 \%)$ \\
\hline & Neurologists & $4(3.2 \%)$ \\
\hline & Neurospecific psychology/psychiatry & $4(3.2 \%)$ \\
\hline & Nonpsychiatric specialists & $14(11.2 \%)$ \\
\hline & Nurses & $74(59.2 \%)$ \\
\hline & Personal support workers & $46(36.8 \%)$ \\
\hline \multirow[t]{8}{*}{ Long-term care } & $\begin{array}{l}\text { Other healthcare professionals } \\
\text { (e.g., physiotherapists) }\end{array}$ & $72(75 \%)$ \\
\hline & General practitioners & $56(58.3 \%)$ \\
\hline & General psychology/psychiatry & $9(9.4 \%)$ \\
\hline & Neurologists & $0(0 \%)$ \\
\hline & Neurospecific psychology/psychiatry & $2(2.1 \%)$ \\
\hline & Nonpsychiatric specialists & $14(14.6 \%)$ \\
\hline & Nurses & $94(97.9 \%)$ \\
\hline & Personal support workers & $70(72.9 \%)$ \\
\hline
\end{tabular}

that, just because the facilities surveyed do not frequently offer care to patients with rare conditions, this does not necessarily mean that those patients are being deprived of care (e.g., families may be accessing private services).

We also reported a small number of regulated healthcare professionals for all conditions across all surveyed institutions, especially in rural settings. A possible solution for this issue may be the implementation of remote training programs for the continuing education of isolated providers. ${ }^{16-18}$ Curran $^{18}$ reviewed the increasingly common role of various modes of tele-education to overcome professional isolation, and Gonzalez-Espada et al. ${ }^{17}$ implemented a successful learning collaborative for pediatric physicians. Formal service providers, as well as support workers, demonstrate a high need for ongoing training opportunities. ${ }^{19,20}$ Furthermore, the paucity of trained (mental) healthcare professionals for persons living with these neurological conditions is inconsistent with such common comorbid conditions as depression, anxiety, and substance abuse. ${ }^{2,21,22}$ Future research should focus on both the enhancement of continuing education opportunities for service providers and determining how to encourage more healthcare professionals to work within these settings.
The exclusion criteria enforced by the majority of service providers encompass prevalent comorbid conditions (e.g., substance abuse disorders), which in turn is likely to limit the accessibility of these services. Exclusion criteria may be in place to ensure that access to care is granted only to those who will benefit, or to those for which care is deemed medically necessary. ${ }^{23}$ Exclusion criteria may also be in place because there are no available and appropriate specialists to provide services to certain subpopulations (e.g., persons with challenging behaviors). Furthermore, some evidence suggests that providers will use exclusion criteria as a means of "cherry-picking" healthier patientspatients who are presumably easier to treat and subsequently use up fewer resources. ${ }^{24}$ Regardless of the rationale for the exclusion criteria, if the few services provided for these neurological patient populations exclude common comorbidities, it is likely that there is no other place where these individuals can seek care.

Lastly, the results from our study highlight a lack of waitlist information among a large proportion of service providers as well as heterogeneous referral patterns across all institutions. These results may support the notion that provision of care for persons with these neurological conditions is uncoordinated, which is consistent with the current evidence that care coordination is an unmet need for people with all neurological conditions examined in our study ${ }^{14}$ Future research should focus on determining why such variability in waitlist maintenance and referral patterns exists, along with the development and testing of new techniques to ensure more coordinated access to care.

\section{LIMITATIONS}

This study acknowledges some limitations. First, it was limited to publicly funded healthcare providers: the sampling frame excluded 730 privately funded LTC facilities. This limits the generalizability of our study findings. Furthermore, the sampling frame was derived from a generic database that may not have been all-encompassing, or may have included programs that do not provide services to those with neurological conditions. The database was also lacking a large number of email addresses, which meant that the link to the survey had to be mailed on paper to potential participants. This created an extra step for respondents, as they had to type the web address into their internet browser (i.e., as opposed to clicking on a link embedded in an email in order to complete the survey). It is likely that this extra step decreased our response rate. Although our response rate is in keeping with those reported by other researchers performing online surveys (e.g., an overall response rate of $22 \%$ by Sills \& Song, $2002^{25}$ ), this lower response rate (and inclusion of only publicly funded organizations) is unfavorable and greatly decreases the generalizability of our results. Despite these limitations, and to the best of our knowledge, ours is the first study of its kind to describe the provision of health and community-based services, as well as the admission criteria, waitlist practices, and referral sources of these services across Canada, including bilingual data collection, and across a variety of neurological conditions.

\section{ConClusions}

As part of the NPHSNC commissioned by the NHCC and Public Health Agency of Canada, the results of this study contribute to our understanding of the current gaps in service delivery and are useful to guide future efforts so that researchers, 
healthcare professionals, and policy makers can work toward creating an integrated and accessible system for persons living with neurological conditions. ${ }^{26}$

\section{ACKNOWLEDGMENTS}

Funding for the study was provided by the Public Health Agency of Canada. The opinions expressed in this publication are those of the authors/researchers and do not necessarily reflect the official views of the Public Health Agency of Canada. SEPM is and has been supported by a Heart and Stroke Foundation of Canada Focus on Stroke Fellowship, by the Toronto Rehabilitation Institute-University Health Network, and by a Canadian Institutes of Health Research Fellowship. KBP is supported by an Enid Walker Graduate Student Award in Women's Health and a University of Toronto Bone and Joint Scholarship. At the time of the present study, SJTG was supported by the Canadian Institutes for Health Research Strategic Training Initiative in Health Research at the Centre for Research on Inner City Health, St. Michael's Hospital. SBJ holds the Toronto Rehabilitation Institute Chair at the University of Toronto.

\section{Disclosures}

Sarah E.P. Munce, Kristen B. Pitzul, Sara J.T. Guilcher, Tarik Bereket, Mae Kwan, James Conklin, Joan Versnel, Tanya Packer, Molly Verrier, Connie Marras, Richard Riopelle, and Susan B. Jaglal do not have anything to disclose.

\section{Statement of Authorship}

SBJ conceived of the larger study together with SEPM and SJTG. SBJ acquired the funding and supervised the research group. SEPM conducted the data analysis and drafted the first version of the manuscript with KBP. SJTG participated in the interpretation of the data analysis and drafting of the first version of the manuscript. TB and MK participated in coordination, acquisition of data, data analysis and interpretation, and drafting of the manuscript. JC, JV, and TP participated in the design, acquisition of data, data analysis, and interpretation, as well as revising the manuscript critically for important intellectual content. MV, CM, and RR participated in the design, data analysis and interpretation, and revising of the manuscript for important intellectual content. All authors have read and approved the final manuscript.

\section{REFERENCES}

1. Neurological Health Charities of Canada. About NHCC; 2017. http://www.nhcc.edu/about-nhcc. Accessed May 22, 2017.

2. Canadian Institute for Health Information. The Burden of Neurological Diseases, Disorders and Injuries in Canada. Ottawa; 2007. https:// secure.cihi.ca/free_products/BND_e.pdf. Accessed May 22, 2017.

3. Colantonio A, Saverino C, Zagorski B, et al. Hospitalizations and emergency department visits for TBI in Ontario. Can J Neurol Sci. 2010;37(6):783-90.

4. Jaglal SB, Munce SE, Guilcher SJ, et al. Health system factors associated with rehospitalizations after traumatic spinal cord injury: a population-based study. Spinal Cord. 2009;47(8):604-9.

5. Caesar-Chavannes CR, MacDonald S. Cross-Canada Forum: National Population Health Study of Neurological Conditions in Canada. Chronic Dis Inj Can. 2013;33(3):188-91.

6. Straus SE, Graham I. the knowledge to action framework. In RycroftMalone J, Bucknall $\mathrm{T}$ editors Models and Frameworks For
Implementing Evidence-Based Practice: Linking Evidence to Action. Hoboken, NJ: Wiley-Blackwell; 2010, P 207-22.

7. Stauffacher M, Flueler T, Krütli P, Scholz RW. Analytic and dynamic approach to collaboration: a transdisciplinary case study on sustainable landscape developing in a Swiss prealpine region. Syst Pract Action Res. 2008;21(6):409-22.

8. HealthCareCAN. Online Guide to Canadian Healthcare Facilities. Ottawa: HealthCareCAN; 2014. http://www.healthcarecan.ca/ product/online-guide-to-canadian-healthcare-facilities/tab-description. Accessed May 22, 2017.

9. Jaglal SB, Guilcher SJ, Bereket T, et al. Development of a chronic care model for neurological conditions (CCM-NC). BMC Health Serv Res. 2014;14:409.

10. Munce SEP, Vander Laan R, Levy C, Parsons D, Jaglal SB. Systems analysis of community and health services for ABI in Ontario, Canada. Brain Inj. 2014;28(8):1042-51.

11. Dillman DA, Smyth JD, Christian LM. Mail and Internet Surveys: The Tailored Design Method. New York: Wiley; 2000.

12. IBM. SPSS Statistical Software, Version 23. Armonk, NY: IBM; 2016.

13. Wilson MG, Lavis JN, Guta A. Community-based organization in the health sector: a scoping review. Health Res Policy Syst. 2012;10:36

14. Munce SE, Hemraj A, Jaglal S, et al. Unmet needs, innovations, and best practices of community-based and health services for individuals with neurological conditions: a scoping review. Paper presented at the Canadian Association of Health Service and Policy Research Conference, Vancouver, BC; 2013.

15. Woods DW, Conelea CA, Himle MB. Behavior therapy for Tourette's disorder: utilization in a community sample and an emerging area of practice for psychologists. Prof Psych Res Pr. 2010;41(6):518-25.

16. Gifford V, Niles B, Rivkin I, Koverola C, Polaha J. Continuing education training focused on the development of behavioral telehealth competencies in behavioral healthcare providers. Rural Remote Health. 2012;12:2108.

17. Gonzalez-Espada WJ, Hall-Barrow J, Hall RW, Burke BL, Smith CE. Achieving success connecting academic and practicing clinicians through telemedicine. Pediatrics. 2009;123(3):e476-83.

18. Curran VR. Tele-education. J Telemed Telecare. 2006;12(2): 57-63.

19. Budych K, Helms TM, Schultz C. How do patients with rare diseases experience the medical encounter? Exploring role behavior and its impact on patient-physician interaction. Health Policy. 2012;105 (2-3):154-64.

20. Booth S, Kendall M. Benefits and challenges of providing transitional rehabilitation services to people with spinal cord injury from regional, rural and remote locations. Aust J Rural Health. 2007;15(3):172-8.

21. Regier DA, Farmer ME, Rae DS, et al. Comorbidity of mental disorders with alcohol and other drug abuse. JAMA. 1990;264 (19):2511-8.

22. Public Health Agency of Canada. The Human Face of Mental Health and Mental Illness in Canada. Ottawa: Public Health Agency of Canada; 2006http://www.phac-aspc.gc.ca/publicat/human-humain06/indexeng.phpAccessed May 22, 2017.

23. Charles C, Lomas J, Giacomini M. Medical necessity in Canadian health policy: four meanings and . . . a funeral? Millbank Q. 1997;75(3):365-94.

24. Olah ME, Gaisano G, Hwang SW. The effect of socioeconomic status on access to primary care: an audit study. CMAJ. 2013;185 (6):E263-9.

25. Sills SJ, Song C. Innovations in survey research: an application of web-based surveys. Soc Sci Comput Rev. 2002;20(1):22-30.

26. Disability Investment Group. The Way Forward: A New Disability Policy Framework for Australia. Canberra: Department of Families, Housing, Community Services and Indigenous Affairs, Commonwealth of Australia; 2009, https://www.dss.gov. au/our-responsibilities/disability-and-carers/program-services/ for-people-with-disability/disability-investment-group/the-wayforward-a-new-disability-policy-framework-for-australia. Accessed May 22, 2017. 